\title{
Marcas no corpo, cansaço e experiência: nuances do envelhecer como professor de Educação Física
}

Sílvia Maria Agatti Lüdorf ${ }^{1}$ Francisco Javier Guerrero Ortega ${ }^{2}$

LÜDORF, S.M.A.; ORTEGA, F.J.G. Marks on the body, fatigue and experience: nuances of aging as a physical education teacher. Interface (Botucatu), v.17, n.46, p.661-75, jul./set. 2013.

This study aimed to gain comprehension of and interpret the meanings that physical education teachers attribute to body and aging, and to investigate how these representations could influence their professional practice. This qualitative study was conducted among 43 teachers at schools and gyms with around 30 years of experience since graduating. The data were evaluated using content analysis. The teachers' aging gave them maturity, experience and confidence in their work. However, the physical body seemed to be separated from the subject, which led to contradictory feelings about aging. In the gyms, there was a certain adjustment to the context of visibility, since the potential of the body and the marks of health imprinted on it are highly valued. Wear and fatigue were particularly felt by the teachers working in schools.

Keywords: Body. Aging. Physical Education. Health. Profession.
Este trabalho objetivou compreender e interpretar os significados que os professores de Educação Física atribuem ao corpo e envelhecimento, e investigar como tais representações influenciariam sua prática profissional. Participaram da investigação, de natureza qualitativa, 43 professores de escolas e academias de ginástica com cerca de trinta anos de formação. Os dados foram tratados mediante análise de conteúdo. O envelhecimento do professor propicia maturidade, experiência e confiança no trabalho, mas o corpo físico parece desprender-se do sujeito, repercutindo em sentimentos contraditórios relacionados ao envelhecimento. Nas academias, há certo ajuste ao contexto da visibilidade, pois são valorizadas as potencialidades e as marcas de saúde impressas no corpo. Já o desgaste e o cansaço são particularmente sentidos pelos professores atuantes em escola.

Palavras-chave: Corpo. Envelhecimento. Educação Física. Saúde. Profissão.

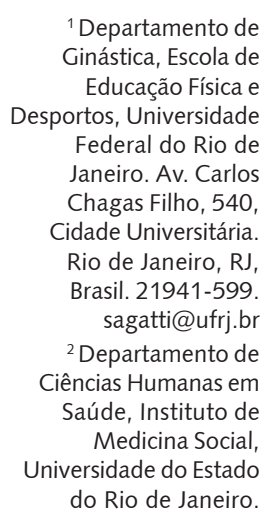

${ }^{1}$ Departamento de Ginástica, Escola de Educação Física e Federal do Rio de Janeiro. Av. Carlos Chagas Filho, 540,

Rio de Janeiro, RJ, Brasil. 21941-599. sagatti@ufrj.br Departamento de Saúde, Instituto de ersidade do Estado do Rio de Janeiro. 


\section{Introdução}

Os profissionais da área da saúde herdaram os modos de conceber (e lidar com) o corpo próprios do desenvolvimento da medicina moderna. A compreensão do corpo experienciado na terceira pessoa, fragmentado e privado de sua dimensão subjetiva, ainda influencia o campo da intervenção em saúde (Ortega, 2008).

Essa concepção de corpo objetificado, em grande medida, permeia também a Educação Física, área que transita entre o campo da educação e o da saúde (Damico, 2011). A título ilustrativo, a compreensão do corpo como uma máquina, ou, ainda, da saúde, restrita ao seu componente biológico, aparecem de modo marcante em cursos de graduação da área (Silva, Silva, Lüdorf, 2011; Hunger et al., 2009; Lüdorf, 2009). Contudo, esta visão de caráter tecnicista desconsidera o imaginário, o simbólico, a história, ou seja, a dimensão cultural e, consequentemente, os diferentes sentidos conferidos ao corpo e à saúde (Le Breton, 2011; Langdon, Wiik, 2010).

O professor ${ }^{3}$ de Educação Física, foco da presente pesquisa, representa o papel de interventor nas/das práticas corporais, com finalidades variadas, dentre as principais: saúde e educação. Além de ter uma atuação diretamente ligada ao corpo e ao movimento, utiliza-se, em função da atividade que desempenhe, de seu próprio corpo como instrumento de mediação destas práticas. Como exemplo, em academias de ginástica, observa-se que o corpo é considerado quase como um "cartão de visitas vivo" (Le Breton, 2006, p.78), uma vez que o professor normalmente é visto como um modelo a ser seguido pelo aluno (Freitas et al., 2011). Além disso, professores de Educação Física demonstram preocupação com aspectos como desempenho e funcionalidade de seu próprio corpo, por relatarem influenciar suas práticas profissionais (Silva, Lüdorf, 2010; Lüdorf, 2009).

Uma vez que o trato e os usos do corpo parecem ser caros ao professor de Educação Física, cabe indagar como seria lidar com essas questões ao longo da carreira, ou em decorrência do processo de envelhecimento. É fundamental esclarecer que o processo de envelhecimento implica uma série de transformações no corpo, não apenas de caráter físico-biológico, mas, sobretudo, sociais.

Desta forma, as representações de envelhecimento, assim como as de corpo e saúde, são social e culturalmente construídas (Le Breton, 2011; Minayo, Coimbra Jr., 2004), e, sob este prisma, serão aqui analisadas. O envelhecimento deve ser visto, nesse sentido, em uma perspectiva relacional, pois se trata de uma experiência subjetiva e intersubjetiva, que depende do contexto, da época e de vários aspectos, dentre eles, do trabalho (Debert, 2007; Stano, 2001).

Em revisão de literatura ${ }^{4}$ sobre o professor de Educação Física e seu processo de envelhecimento, foram encontrados poucos estudos que abordam a temática. No âmbito das academias de ginástica, Coelho Filho (2000/1) identificou dificuldade de manutenção dos professores à medida que envelhecem, enquanto Palma et al. (2007) detectaram certa 'aposentadoria precoce', sobretudo em virtude de elevadas cargas horárias e de esforço físico. Quanto ao ambiente escolar, Faria Júnior e Faria (1999) se referem à perda dos níveis de performance física e desportiva em decorrência da idade, o que poderia ter implicações na elaboração de aulas. Silva e Lüdorf (2010) identificaram que a maturidade gera credibilidade e confiança no trabalho desenvolvido, além de implicações peculiares à profissão, como o desgaste físico, dentre outros fatores. Observa-se que são raras as produções que discutem o envelhecimento do professor de Educação Física sob a ótica do próprio ator social, buscando conhecer os significados do envelhecimento à luz da realidade vivida e do contexto profissional e social no qual está inserido.
${ }^{3}$ Com a regulamentação da profissão de Educação Física, a partir da promulgação da Lei ${ }^{\circ}$ 9.696/98, que trata da criação do Conselho Federal e Regional de Educação Física (CONFEF e CREF), passou-se a utilizar o termo "profissional de Educação Física" para os egressos do curso de Bacharelado, formados para atuar nos ambientes considerados não formais (academias, clubes etc). O curso de Licenciatura continuaria a formar os professores que atuariam junto à Educação Básica. Entretanto, neste trabalho, considerandose que a dimensão de intervenção, independente do ambiente, é de natureza pedagógica, optamos por utilizar o termo "professor de Educação Física".

${ }^{4}$ A revisão de literatura foi realizada nas bases de dados: LILACs, Scielo, Medline, Eric e Scopus, bem como em periódicos de Educação Física não indexados. 
${ }^{5}$ Ainda que alguns dos professores desempenhassem várias atividades, se reconheciam em uma atividade principal ou possuíam maior tempo de atuação em dado âmbito.

${ }^{6}$ Ver em: www.pesquisanespefe.com.br

\footnotetext{
${ }^{7}$ As questões estão disponíveis no sítio mencionado na nota anterior, referente ao ambiente virtual do questionário.
}

Desvelar as estratégias, sentimentos e perspectivas em relação ao envelhecer permitiria analisar as particularidades e universalidades referentes a este grupo (Debert, 2007). Espera-se, também, que possa contribuir para ampliar a compreensão e o conhecimento sobre as nuances e especificidades não apenas deste, como, eventualmente, de outros profissionais que atuem nos campos da saúde e da educação.

O objetivo deste trabalho, em um primeiro momento, é compreender e interpretar os significados que os professores de Educação Física atribuem ao corpo e ao envelhecimento. Além disso, investigar em que medida tais representações influenciariam sua prática profissional, mais especificamente, os trabalhos desenvolvidos em academias de ginástica e em escolas.

\section{Procedimentos metodológicos}

A presente investigação é de natureza qualitativa, pois visou explorar o espectro de opiniões e os diferentes significados sobre determinado assunto (Gaskell, 2003), bem como fornecer possíveis interpretações. Para Turato (2003), buscar o significado de fatos, sentimentos ou assuntos é tratar de representações que dão molde à vida das pessoas e que são compartilhadas culturalmente por determinado grupo social, neste caso, os professores de Educação Física.

A seleção dos sujeitos privilegiou alguns critérios: o professor deveria ter se formado em Educação Física, no mínimo, há 25 anos; estar atuando profissionalmente; ser oriundo de diferentes âmbitos de trabalho, sobretudo, de academias de ginástica e de escola. O primeiro critério foi adotado em função do alerta de Debert (2004) sobre a impropriedade de se categorizarem os sujeitos em função da faixa etária. Professores que atuam há mais de 25 anos na carreira docente estariam em fases chamadas de serenidade e desinvestimento (Huberman, 2007), próximos da aposentadoria, um marco no processo de envelhecimento ligado à legitimação de direitos na sociedade (Debert, 2007). Quanto ao âmbito de atuação ${ }^{5}$, pretendeu-se compreender a variedade de representações das pessoas no seu mundo vivencial (Bauer, Aarts, 2003).

Tendo em vista que a combinação de técnicas visa imprimir rigor, amplitude e profundidade à investigação (Denzin, Lincoln, 2006), foram utilizadas entrevistas qualitativas e questionários para a coleta de dados, aliados a notas em um diário de campo.

A entrevista qualitativa, conforme Gaskell (2003), fornece dados para a compreensão das relações entre os atores sociais e sua situação. Os relatos das trajetórias profissionais permitiram compreender como as representações expressas nos discursos foram construídas ao longo da vida e se relacionariam com a atuação na profissão.

Foi também desenvolvido um questionário, disponibilizado em um ambiente virtual ${ }^{6}$ e divulgado em listas de discussão ligadas à Educação Física. Com essa estratégia metodológica, buscou-se propiciar privacidade, anonimato e autonomia de resposta (Flicker, Haans, Skinner, 2004). Se, por um lado, as entrevistas possibilitam a riqueza da interação, o aprofundamento de determinadas questões e a observação das reações, comportamentos e contexto do entrevistado (registrados no diário de campo), os questionários permitem respostas diretas, objetivas e, muitas vezes, sem pudores, em virtude de não haver exposição ou identificação de quem o responde.

O roteiro de questões ${ }^{7}$ foi previamente validado por especialistas da área e aplicado em fase exploratória (Silva, Lüdorf, 2010). Além de dados como idade, 
gênero, local(is) de atuação e informações sobre a graduação e eventuais cursos de pós-graduação, as questões versavam basicamente sobre: a) Trajetória como professor de Educação Física; b) Prática pedagógica no início da carreira e na atualidade; c) Envelhecimento e carreira; d) Corpo e envelhecimento. Contudo, nas interações pessoais, em raras ocasiões foi utilizado em sua totalidade. Ao relatarem seu percurso profissional, por vezes, os demais assuntos eram abordados sem, necessariamente, seguir a ordem ou haver necessidade de realizar as perguntas.

Para a discussão aqui empreendida, serão utilizados os dados de 43 sujeitos. Destes, 14 foram entrevistados, cujas características centrais são: possuem de 29 a 38 anos de formados; idade variando de cinquenta a sessenta anos; alguns já aposentados em empregos públicos ligados a escolas, mas ainda atuantes na profissão; sete do gênero masculino e sete do feminino. Destaque-se que todos os professores trabalham no Rio de Janeiro.

Dos questionários respondidos ${ }^{8}$, foram selecionados 29 respondentes que se encaixavam no perfil desejado, ou seja, possuíam tempo de formação que variava entre 26 e 39 anos e idade de 51 a 63 anos. Em virtude do alcance da internet uma das vantagens dessa técnica - o grupo acabou composto por 16 homens e 13 mulheres, provenientes de 16 estados brasileiros ${ }^{9}$.

Os dados foram tratados com base na análise de conteúdo, conforme processo descrito por Turato (2003), que envolve as etapas de leitura flutuante, categorização e subcategorização, segundo critérios de relevância e repetição. Este processo possibilitou destacar dois eixos temáticos: 1) Significados atribuídos ao corpo e ao seu envelhecimento; 2) Envelhecimento, corpo e a prática/carreira de professor de Educação Física.

Ainda que inter-relacionados, pretende-se discutir, no primeiro eixo, as concepções de corpo, de envelhecimento e da própria profissão, no intuito de moldar o contexto sociocultural mais amplo. Já no segundo, serão abordadas as singularidades relacionadas aos diferentes âmbitos de atuação.

Os professores entrevistados serão referidos por P1, P2 etc. Já os que responderam aos questionários serão apresentados como PQ1, PQ19 etc., conforme o código gerado a partir da ordem de resposta. Serão indicados, também: gênero, âmbito de trabalho (academia de ginástica - acad. ou escola esc.) e idade, para conhecimento do perfil dos participantes.

O presente estudo foi aprovado pelo Comitê de Ética em Pesquisa do Instituto de Estudos de Saúde Coletiva da Universidade Federal do Rio de Janeiro.

\section{Resultados e discussão}

\section{Significados atribuídos ao corpo e ao seu envelhecimento}

Os professores participantes desse estudo, em dados momentos, apontaram características que constituíam a identidade do professor de Educação Física, tais como: ativo, sociável, bem-humorado, bem-disposto, criativo, dentre outras:

\footnotetext{
"Todo professor de Educação Física tem por excelência, a alegria natural, a disposição, a liderança nata, a descontração. E, eu, que sempre exercitei todos esses meus lados, faço uso, com muito mais vivência, agora, que estou quase uma terceira idade". (PQ59, professora esc., 55 anos)
}

${ }^{8}$ O questionário foi disponibilizado na Internet, indistintamente, a professores de Educação Física. Por isso, foram totalizados 268 questionários respondidos, entretanto 29 se enquadraram no perfil estudado nessa oportunidade.

${ }^{9}$ São eles: RJ, SP, MG, RO, MS, CE, AM, PR, DF, RS, GO, PA e RN. 
Talvez essas características ajudem a compreender os significados que foram atribuídos ao envelhecimento por esse grupo específico, até certo ponto, contraditórios. Ao mesmo tempo em que afirmavam "nunca ter pensado nisso" ou que "não aparentavam a idade", demonstravam, nas falas, exemplos de que o passar do tempo estava alterando a dinâmica relacional, profissional e determinados comportamentos. Por vezes, essas percepções estavam vinculadas a marcas no corpo:

\begin{abstract}
"Começa a aparecer a ruga, o corpo começa a modificar. Tem horas que eu fico um pouco assustada, quando eu olho, eu falo: "caramba, eu não tinha essa barriga, [...]". Mas eu acho que eu tenho que encontrar a beleza do envelhecimento, "estou assim" e na hora eu fico meio chocada, mas eu falo: "vamos embora, vamos correr atrás". Vou cuidar para ver se eu estou bem, se eu consigo brincar, dançar, se eu consigo fazer uma caminhada". (P10, professora esc., 53a)
\end{abstract}

"Eu já to com 55 anos, né? Uma hora você tem que parar, porque é cansativo, né? Você com essa idade, você correndo atrás de criança na quadra com o apito na boca é um pouco complicado, mas eu gosto, é prazeroso, entendeu? Eu acho que é prazeroso [...]. Eu não me sinto com a idade que eu tenho, nunca me senti na minha vida e na verdade nunca me deram a idade que eu tenho, [...] eu não me sinto velha, não sou velha, mas estou caminhando para isso, né? Então, daqui pra frente o tempo de vida vai mudando, vai diminuindo, né? [...] eu sei que estou envelhecendo, mas eu acho que eu tenho uma cabeça boa, entendeu?". (P9, professora esc., 55a)

"Pra mim essa consciência de envelhecimento tá me aparecendo um pouquinho, vamos dizer assim, de uns 3 anos pra cá, que foi quando eu entrei em menopausa. [...] essa coisa da queda hormonal pra mulher é muito significativa. No início você começa a sentir, sabe, uma dificuldade maior em subir num degrau que você vem correndo e sobe, como fazia. Você se sente um pouco mais pesada... é... você passa um pouco, como é que eu vou te dizer... o envelhecimento físico mesmo. Eu não me sinto envelhecida mentalmente. Fisicamente mais, né? O que aconteceu com o meu corpo: eu engordei mais, mais rápido, eu engordei mais rápido". (P13, professora acad., 54a)

"O professor de educação física envelhece no corpo, na mente há sempre uma atividade que ele está disposto a exercer". (PQ170, professora esc., 55a)

Dois aspectos, interligados, chamam a atenção nos trechos apresentados. O primeiro se refere à dicotomia corpo e mente, que parece se exacerbar nessa fase da vida e, talvez, ainda mais sentida no caso estudado, em virtude das características da profissão. Conforme os professores, a mente continua nova e produtiva, contudo, o corpo, restrito à sua parte física, é que dá sinais de envelhecer. Conforme Le Breton (2011, p.226), o envelhecimento " [...] em termos ocidentais, marca a redução progressiva do corpo, uma espécie de escravização a uma dualidade que opõe o sujeito ao seu corpo e o torna dependente deste último."

O segundo aspecto é a aparente dificuldade em aceitar o fato de estar se sentindo "mais velho", como pode ser visto na utilização dos adjetivos "assustada", "chocada", "estranha", "angústia", quando se referem ao envelhecimento. Essas sensações emergiram com mais intensidade nos depoimentos das professoras, o que, de certo modo, corrobora com os juízos construídos socialmente, de que o impacto do envelhecimento é mais sentido pelas mulheres. Para Le Breton (2011, p.234):

A velhice marca desigualmente, no juízo social, a mulher e o homem. Vemos aqui, independentemente da idade dos atores, a permanência de uma imagem social oposta do homem e da mulher que faz do primeiro um sujeito ativo, cuja apreciação social repousa menos sobre uma aparência do que sobre certa tonalidade de sua relação com o mundo, e 
da segunda um objeto de encanto, passível de se degradar ao longo do tempo, ao contrário do homem, que permanece sempre um sedutor em potencial.

Em outros casos, os professores relatam eventos ou fatos que fizeram com que se sentissem mais velhos, em oposição a serem mais novos, como se fossem marcos da chegada do envelhecimento:

“[...] a vinda da neta, para mostrar que tem muito pela frente. Vontade de estar com ela. Tá sendo super legal porque ai você vai renovando, porque eu pensei: "meu Deus do céu"! Eu nunca pensei... pensei que já tava naquela fase quase na linha de chegada, já é uma outra partida, uma outra linha de chegada lá na frente, então acho que eu fui beneficiado de alguma maneira, e eu acho que a minha profissão de alguma maneira mostrou isso né, me direcionou a isso". (P1, professor acad., 52a)

"Por volta dos 40 anos eu fui...eu fui participar...eu fiz uma atividade no final de semana com os alunos, fui fazer um futebol, mas de repente eu percebi que não era mais, eu não podia correr como 15 anos, então, daí então...eu acho que o envelhecer...eu acho que tem que acompanhar o que ta acontecendo pra você envelhecer bem, né?". (P8, professor esc., 60a)

"Honestamente, às vezes eu me sinto cansado, é eu me sinto, eu me sinto às vezes, e eu já me peguei nesse mês de março reclamando desse mês, foi um mês cheio. Sem paradinhas, não é? Porque [...] a coisa me incomoda assim, então quando vem um mês de trinta e um dias, pleno, cheio, pô, que mês chato, não tem uma brechinha, [...] eu me preocupo e eu acho que isso é uma... um reflexo do envelhecimento, o cansaço, a vontade de, de que eu tivesse um descanso a mais, não é?". (P5, professor esc., 53a)

Para Corbin (2003), o corpo se manifesta à pessoa através de sensações que, por sua vez, estão ancoradas em significados. Ao desenvolver estudos sobre saúde e doença, o autor argumenta que a linguagem corporal e as sensações são muito importantes, pois as pessoas não falam a linguagem do sintoma, mas de mudanças nas sensações ou na aparência. Esta visão é análoga ao que foi observado nos depoimentos em relação ao processo do envelhecimento. As marcas e marcos corporais estão relacionados às alterações ou dificuldades sentidas no corpo e, também, no cotidiano, como: diminuição de desempenho, chegada da menopausa, descoberta de doença como a hipertensão (P5), mudança de status no próprio local de trabalho, ou, ainda, o cansaço da rotina laboriosa, dentre outros.

Nota-se que os professores entrevistados estão vivenciando um momento de transição, talvez pela própria fase em que vivem, com cerca de trinta anos de formados. Possuem características ainda relacionadas ao "ser jovem", mas sentem, conforme suas falas, certas alterações ligadas ao "ser velho", o que os leva a transitarem por essas formas de identidade, não sem tensão, em função não apenas do seu olhar, como do olhar escrutinador do outro:

"Isso eu falo para os garotos, outro dia tava falando até com o F., que ta dando um bocado de aula [...] ao mesmo tempo que você é um professor de educação física, jovem, boa pinta, tem um monte de gente que cerca ele aqui, um monte de namorada, aquelas coisas todas e progressivamente essas coisas vão diminuindo. Lógico, não dá para ser o cara da hora, agora o cara é outro, eu sempre falo isso, lógico, é normal isso, se você não entender isso, se você não tiver uma cabeça legal, pode ser que te traga problema, em função da sua própria vida mesmo, de você começar a se desmotivar e tal". (P1, professor acad., 52a)

“Eu não consegui concluir (o Mestrado) porque me separei e daí foi uma confusão, parei, fiz algumas matérias lá, [..]. Perdi tudo e agora to... Olha quanto tempo tem, perdi tudo, agora que eu vou fazer o mestrado... Esse mestrado... "Ah, você tá velha pra fazer o mestrado". 
Esse mestrado talvez me abra as portas, mas eu não to muito interessada se vai abrir ou não, eu gosto de estudar, eu gosto muito de estudar...". (P3, professora acad., 53a)

Mesmo que, no contexto contemporâneo, as noções de novo ou velho sejam cada vez mais relativizadas e nuançadas, havendo dificuldades em se demarcá-las, a juventude deixa de ser um estágio na vida para se transformar em valor, "um bem a ser conquistado em qualquer idade" (Debert, 2004, p.21). Talvez devido a esse fato, certa tensão tenha sido particularmente sentida nos discursos analisados, ao manifestarem receio ou temor de se sentirem velhos.

\section{Envelhecimento, corpo e a prática/carreira de professor de Educação Física}

O processo de envelhecimento e o trato ou usos do corpo para professores de academias de ginástica e de escola apresentam nuances dignas de nota, como poderá ser visto.

\section{$\mathrm{Na}$ academia de ginástica}

Em uma primeira tentativa, houve dificuldade em localizar professores com cerca de trinta anos de formados, atuantes em academias de ginástica, o que parecia confirmar a suspeita de que este âmbito privilegiava os profissionais mais novos.

Entretanto, a partir de indicações, foi possível encontrar professores que trabalham no mercado de academias praticamente desde que se formaram. Isso significa que fizeram parte do processo de criação e proliferação dessas instituições, que recrudesceram significativamente no final da década de 1980 e, principalmente, na década de 1990 (Bertevello, 2005), como pode ser atestado:

“Em 80 eu corri atrás de montar uma academia e montei né? Montei pequenininha, com 200 metros quadrados [...] Aí, depois, aumentei pra uma de 250 metros quadrados e depois vim pra cá. Aí eu acabei fechando lá porque a academia deu cria. [...] foi uma das primeiras do bairro, né? Aí começou a abrir, chegou a ter seis academias em volta, né?". (P4, professor acad., 60a)

Esses professores, cujas atividades ao longo da carreira se centraram nas academias, desenvolveram algumas estratégias de manutenção nesse ambiente. Podem ser proprietários destes estabelecimentos, como o caso de P4 que, aliás, é exemplar do próprio desenvolvimento do mercado das academias. Instalações de pequeno porte, embora numerosas nas décadas de 1980 e início de 1990, foram sucumbindo às maiores, que ganhavam força no cenário do fitness com instalações amplas e aparelhagem moderna. Atualmente, ele é proprietário de outra academia e, conforme observado no próprio local, quando da entrevista, além de dono, P4 era o único professor do horário, sendo, também, o que recepcionava os alunos e fazia avaliação física. Nos dizeres dele:

“[...] aqui eu sou meio empresário, meio professor, né? Mas eu acho que é assim que eu consigo sobreviver, né? Se eu tiver que pagar os professores, botar aqui pra ficar em casa, eu não vou conseguir viver. Eu vivo porque eu associo, você vê que eu trabalho na secretaria, dou aula, tá entendendo.. e...e administro, né?". (P4, professor acad., 60a)

Outra estratégia é possuir alunos de treinamento personalizado (personal trainer), fato que possibilita uma renda muito superior à que normalmente se recebe em academias. Nesses casos, o trato com os alunos torna-se diferenciado, na medida em que o contato é mais próximo e ocorre certa fidelização do mesmo, que acaba acompanhando o professor durante anos. Esse trabalho, contudo, é resultado de muito tempo de investimento pessoal e profissional: 
“Às vezes a pessoa quer ser personal, porque hoje em dia financeiramente é o que dá mais dinheiro mesmo, e às vezes o garoto é novo e ele tá te vendo dar aula todo dia para um monte de aluno e ele acha que isso caiu do céu. Ai você fala "olha, não é assim, as coisas não acontecem assim, as coisas acontecem com muito trabalho, dedicação". [...] Você vai fazendo grandes amizades [...]". (P1, professor acad., 52a)

A permanência nas academias pode ocorrer quando o professor assume cargos de coordenação (ou da própria academia, ou de setores específicos, como a musculação, ginástica etc.), ou, ainda, ocupa posição de destaque por ser "detentor" de um saber relacionado a uma determinada modalidade, como no caso da ginástica localizada, aulas específicas ou de dança.

Possuir um diferencial de atuação e estar constantemente inovando nas aulas também são estratégias que permitem atrair muitos alunos e, consequentemente, manter-se nas academias. A necessidade frequente de atualização é ressaltada como um aspecto central para se ocupar essa posição de distinção:

\footnotetext{
"Todo mundo tenta estar o mais atualizado possível, eu mais que todo mundo, por conta da minha idade né? Eu não posso ta parada no tempo. Eu tava hoje conversando na cantina com um rapaz, ele falou: "o seu diferencial dos outros da sua época é impressionante! Você tá sempre atual, você ta sempre buscando alguma coisa pra estar dentro do que ta acontecendo". Ué, eu falei: "ué, senão eu vou morrer né?". (P3, professora acad., 53a)

"Eu tenho um contexto muito mais amplo porque eu trabalho desde uma pessoa com idade até o adolescente, eu trabalho desde lesão até um trabalho estético. Então isso faz com que eu fique estudando o tempo todo, [...] ai você não deixa de estudar". (P1, professor acad., 52a)
}

O que se pode observar, nesses casos, é que os professores mais experientes continuam a ser uma opção interessante no mercado das academias, uma vez que fidelizam o aluno em virtude do trabalho satisfatoriamente executado e arregimentam muitos seguidore ${ }^{10}$. Além disso, conforme as observações de campo, tais professores não aparentam a idade que possuem, além de possuírem estereótipos corporais condizentes com os atributos considerados relevantes não apenas nesse ambiente, mas na sociedade, como esbelteza e boa forma.

Esses achados podem ser interpretados à luz da argumentação de Ortega e Zorzanelli (2010) de que, na atualidade, os aspectos-chave da subjetividade são definidos em termos corporais e biomédicos, o que gera uma série de preocupações físicas e estéticas. Tal proposição parece se manifestar, ainda mais, no profissional que lida com as práticas corporais, como o professor de Educação Física.

Uma evidência é o destaque, no contexto das academias de ginástica, dado à representação do corpo como outdoor. Trata-se do componente estético ou visível do corpo que, quando adequado aos parâmetros corporais vigentes, funciona como propaganda para os alunos. Representa, assim, o ideal de saúde e de boa forma que, em última instância, é o produto a ser "vendido" nas academias:

“Hoje eles ficaram brincando comigo, que eu tinha esquecido a camiseta e eles me emprestaram uma camisa toda apertadinha. Ai a

\footnotetext{
${ }^{10}$ Em alguns casos, os alunos acompanham os professores até mesmo quando trocam de academia. Houve um caso emblemático no Rio de Janeiro em que uma academia de grande porte teve de encerrar suas atividades. Vários dos alunos seguiram seus professores, como visto em reportagem do jornal de maior circulação da cidade (Brisolla, 2012)
} 
moça (da recepção) falou: "já pensou se você tivesse gordinho, passar com uma camiseta toda apertadinha, gordinho?" Isso é legal porque você vê que você vai envelhecendo, mas o seu corpo vai, praticamente ele envelhece junto, mas ele vai dando o sinal que você vai dando para ele, vai te mostrando o que você vai dando para ele, e é gratificante que você sabe que você ta envelhecendo, mas que você ta envelhecendo bem". (P1, professor acad., 52a)

"No começo eu fiquei mais assustado, pois trabalhava em academia e estava ficando velho, fora do padrão academia, garotão desportista. Depois, comecei a observar que o fato de estar ficando velho e com saúde, fora do padrão sedentário, me dava um ponto a favor. Somos nossos próprios outdoors, então percebi que estar na minha idade e em forma me dava um ponto a favor, sou o exemplo de que podes amadurecer com saúde, agora me sinto bem com isso". (PQ64, professor acad., 51a)

Nesse âmbito, portanto, aparece naturalizado o fato de ser cobrado do professor um estereótipo corporal que se adeque aos imperativos contemporâneos de beleza e juventude (Lüdorf, 2009). A preocupação, por exemplo, com os cabelos brancos e sua associação com aspectos negativos do envelhecimento, compartilhados pelo senso comum, como poderá ser visto, é ilustrativa desta naturalização:

"(o envelhecimento propicia) menos agilidade e espaço na profissão. Hoje em dia cabelos brancos não transmitem experiência, mas sim fraqueza". (PQ76, professor acad., 63a)

“Nossa, não tem noção de como foi, porque eu fiquei fazendo a minha cabeça durante três anos assim: "eu vou cortar, eu vou deixar o meu cabelo branco, eu vou deixar o meu cabelo branco". Fui fazendo a minha cabeça e fui fazendo a cabeça de quem mais ou menos tava perto de mim. Mesmo assim teve reações adversas até dizer chega, eles ficaram horrorizados. Olha, eu não deixei de ser eu né?". (P3, professora acad., 53a)

Analogamente ao que argumenta Shilling (2005), o capital corporal, no ambiente das academias de ginástica, poderia ser convertido em capital econômico e social, estando aliado ao capital, poder-se-ia dizer, da experiência. Estes fatores possibilitam que o professor de Educação Física mantenha-se em destaque na profissão e produtivo ao longo da carreira, não sem esforço ou sacrifício. Foi observado que vários destes professores mantêm uma rotina de treinamento, realizando atividade física de modo regular e/ou, por vezes, acompanhando os próprios alunos, como no caso de aulas individualizadas ou, ainda, em grupo onde seja necessária a demonstração.

Ao analisarmos os dados dos questionários, foi possível detectar uma tendência que auxilia a compreender a impressão inicial sobre a dificuldade de se achar professores de academias com mais tempo de carreira. Dos 29 respondentes, boa parte já havia trabalhado em academias, porém apenas nos primeiros anos depois de formado. Posteriormente, direcionaram-se a outros trabalhos, como projetos sociais, clubes, e, eventualmente, continuavam ou iam para a escola. A esse respeito, caberia um aprofundamento nesse segmento específico, uma vez que, conforme Coelho Filho (2000/1), há uma tendência de os professores mais velhos perderem espaço nas academias. Por outro lado, não se pode descartar que podem não ter permanecido devido a uma escolha pessoal, ou por se sentirem insatisfeitos com o trabalho, o que mereceria ser elucidado.

\section{$\mathrm{Na}$ escola}

Uma das suspeitas iniciais era de que o professor de Educação Física procuraria a escola em momento mais adiantado da carreira, pelo fato de proporcionar, sobretudo no caso de concursos públicos, certa estabilidade profissional. Esse argumento não parece se sustentar, ao menos nos professores investigados. 
Dados provenientes dos questionários e entrevistas demonstraram uma tendência de manutenção na escola, embora desenvolvessem outros trabalhos durante a carreira:

"Como professor eu dava aula no SESC, e eu era (professor) do município do Rio de Janeiro também [...], fui coordenador de esporte [...], depois eu vim pra cá, no colégio [...]". (P8, professor esc., 60a)

"Sou formado há 32 anos e atuei em academia por 8 anos e escola de ensino privado, até que fui aprovado em concurso público estadual (1982) e municipal (1985). Em 2005 fui aprovado em concurso para o ensino federal". (PQ46, professor esc., 52a)

O fato de trabalhar por muitos anos na escola pode explicar uma das associações com o envelhecimento que emergiram dos dados: os professores manifestaram satisfação em contribuir para educar. Os longos anos dedicados à profissão permitem acompanhar as diferentes fases de vida dos alunos:

“[...] às vezes me chateia, quando um aluno que eu to falando o aluno não ta me ouvindo, mas aqueles que te ouvem, aquilo ali é uma coisa que me dá muito prazer e isso é o que mais se manifesta em mim, um orgulho, da profissão até, é essa questão de transformar pessoas [...] Na sala, manifestando minhas brincadeiras, eu sempre produzindo, passando alguma coisa que servirá na profissão, na carreira profissional desse ex-aluno, enfim, num futuro médico, um futuro professor, engenheiro, a gente sempre encontra né? Isso, isso aí é uma coisa que me dá um prazer muito grande". (P5, professor esc., 53a)

“[..] se amamos o que fazemos, o espírito também não envelhece, lidar com jovens é muito gratificante, saber que fazemos parte do crescimento humano. São muitas vitórias e isso nos engrandece, principalmente na área de educação física". (PQ170, professora esc., 55a)

Reside, nesse aspecto, uma característica básica da docência, conforme Stano (2001), de preparar-se para ensinar/educar o outro, processo este intrincado ao percurso profissional. O modo de lidar com o aluno também se modifica a partir do amadurecimento e do saber construídos ao longo da trajetória docente, como também detectado em Folle e Nascimento (2011).

Neste sentido, a experiência emergiu como um aspecto positivo associado ao envelhecimento e à prática do professor:

"As experiências vão se acumulando e você fica mais preparado para responder a demandas profissionais cada vez mais amplas". (PQ2, professor esc., 58a)

"Para mim é um motivo de satisfação, pois a cada ano que passa, mais sou feliz com as experiências que totalizo". (PQ42, professora esc., 56a)

"(o que muda com o envelhecimento) Na melhoria da abordagem dos assuntos, na qualidade da relação com os alunos, na paciência com as dificuldades, na valorização da tentativa em detrimento do sucesso". (PQ179, professor esc., 50a)

Ainda que se considere o caráter singular das carreiras, construídas com base na história pessoal e profissional, influenciadas por uma série de condições e oportunidades de trabalho, nível de formação e de atualização, sem mencionar os aspectos psicoafetivos e o contexto mais amplo das políticas públicas atreladas à profissão, o tempo é uma variável importante neste processo (Nóvoa, 2007; Tardif, 2002).

Em princípio, os professores estudados estariam nas fases finais de carreira (serenidade e desinvestimento), entretanto foram identificados elementos associados à fase de estabilização 
(Huberman, 2007), como o sentimento de competência crescente e a acentuação do grau de liberdade de atuação. Tais características foram detectadas também por Folle e Nascimento (2011), o que corrobora a ideia de que as fases de carreira não são estanques.

O argumento de Debert (2007) de que é fundamental compreender as representações, práticas, circunstâncias de vida e de trabalho associadas ao envelhecimento, não poderia ser mais pertinente e emblemático no caso do professor de Educação Física atuante em escolas. O ambiente escolar, se proporciona o contato e acompanhamento das crianças e adolescentes, no que se revela algo prazeroso relacionado à profissão, exige muito do docente em relação ao próprio corpo.

A importância atribuída ao corpo como instrumento de trabalho para o professor de Educação Física já havia sido apontada (Silva, Lüdorf, 2010), no entanto, ao se aprofundarem os significados atribuídos ao envelhecimento e ao corpo na profissão, emergem duas dimensões do corpo que estão imbricadas: a funcional e a física. Na opinião dos sujeitos, estas dimensões transpareceram de modo recorrente, ao se referirem ao cansaço, diminuição de disposição para realizar atividades laborais, limitação da capacidade (motora e física) de realizar exercícios, elementos esses ligados à natureza do trabalho, como pode ser visualizado nos exemplos:

"Cada vez mais tenho que me superar para que os alunos [...] se interessem pelas atividades. Em relação ao aspecto físico também, um acervo motor, muito mais habilidade e técnica, mas ao mesmo tempo uma capacidade física a nível, articular, muscular e resistência física tendo que se superar cada vez mais por questões hormonais". (PQ106, professora esc., 52a)

“Tinha coisas que eu fazia quando eu comecei a trabalhar na rede municipal, eu dava aula em Caxias, morando no Meier, eu não sei se hoje eu teria capacidade física pra fazer que eu fazia naquela época, né?". (P12, professor esc., 54a)

"A gente vai envelhecendo e eu trabalhando com criança, obviamente você no final, você já não tá com pique pra estar acompanhando criança, entendeu?". (P14, professora esc., 53a)

“Na escola, a mesma coisa. Muito mais até. A pessoa de idade na escola, trabalhar com criança, como era o meu caso, "ah, perde o pique...", você vai chegar e vai deixar rolar uma bola". (P13, professora esc., 54a)

A preocupação com a funcionalidade foi mencionada por professores em fase intermediária de carreira (Silva, Lüdorf, 2012), porém se tratava de algo ainda abstrato; ao passo que os professores próximos à aposentadoria, aqui estudados, se referem à mesma de modo mais concreto, citando exemplos relacionados à prática profissional. Observa-se que o passar do tempo se manifesta no que, para Le Breton (2011, p.145), seria uma forma de dualidade sentida pelo sujeito, quando se sente "cativo de um corpo que o abandona".

O cansaço pode estar atrelado às condições de atuação profissional do docente (Pecora, Anjos, Paredes, 2010). Contudo, parece sobressair no de Educação Física, uma vez que é normalmente parte de sua rotina: carregar material, expor-se ao sol, demonstrar exercícios, dentre outras características peculiares que "pesam" diante dos muitos anos de trabalho:

“Eu não consigo imaginar um profissional desse nessa área dando aula prática sem disponibilidade corporal para estar ali em pé, falando, arrumando material ou corrigindo aluno, isso a própria atividade profissional demanda, disponibilidade física, essa coisa do desgaste energético mesmo. É diferente de um trabalho que você fica mais sentado". (P2, professora esc., 52a)

"[...] cansativa, o sol é um dos maiores problemas e também a paciência, que com o passar dos anos está se esgotando". (PQ154, professora esc., 51a) 
"Cansado, desgastado... e muito desvalorizado profissionalmente, nas escolas, pelo corpo técnico, financeiramente". (PQ199, professor esc., 51a)

"O fôlego não é o mesmo, embora a vontade de trabalhar e produzir continue em evidência. Muitas vezes o cansaço não ajuda na condução adequada da aula". (PQ242, professora esc., 54a)

Estudos de caráter ocupacional e sobre a qualidade de vida do professor de Educação Física têm surgido com mais frequência na literatura (Farias et al., 2008; Folle et al., 2008; Lemoyne et al., 2007), e apontam para importantes aspectos a serem discutidos no âmbito profissional e de políticas públicas. Sem desconsiderar tal necessidade, à luz dos dados analisados, o cansaço relativo ao corpo e, em grande medida, relacionado à profissão, constitui-se em elemento marcante.

Observa-se, portanto, que o tempo de dedicação e o tipo ou ramo de trabalho revelam-se marcadores interessantes para se avançar nas interpretações sobre como o passar dos anos influencia a carreira - neste caso, a de professor de Educação Física, mas, potencialmente, a dos profissionais de saúde e de educação em geral.

\section{Considerações finais}

Diante do exposto, pode-se concluir que o processo de envelhecimento, neste caso, do professor de Educação Física, quando analisado em sua dimensão sociocultural, apresenta nuances e contradições que merecem ser consideradas.

Em um contexto de alta visibilidade do corpo e de valorização de princípios voltados à saúde e performance, o professor de Educação Física pode ser associado a significados compartilhados culturalmente, que remetem ao dinamismo, modelo de corpo e de práticas corporais ditas saudáveis. Contudo, as evidências empíricas indicam que o olhar deve ser aprofundado e relativizado, sobretudo em se tratando daquele que atua há muitos anos na profissão.

Se o processo de envelhecimento do professor, por um lado, propicia a maturidade, experiência e confiança no trabalho desempenhado, que são elementos centrais e valorizados na prática cotidiana, o corpo físico parece desprender-se do sujeito, abandonando-o gradativamente, repercutindo em sentimentos contraditórios relacionados ao envelhecimento. Nas academias de ginástica, há certo ajuste ao contexto da visibilidade, pois se trata de ambiente que valoriza o prolongamento das potencialidades e das marcas de saúde e longevidade impressas no corpo dos professores. Já o desgaste e o cansaço do corpo são particularmente sentidos pelos professores atuantes em escolas.

Diante da complexidade que ronda a temática, destaca-se a imperiosa necessidade de se avançar nas investigações sobre envelhecimento tendo em vista as diferentes realidades, tanto do professor de Educação Física, como de outros profissionais que lidam com intervenções em saúde e em educação.

\section{Colaboradores}

A autora Sílvia Maria Agatti Lüdorf delineou o artigo, no qual apresenta dados derivados de pesquisa orientada por Francisco Javier Guerrero Ortega. Ambos os autores participaram da discussão sobre a estrutura e redação do artigo. O orientador efetuou revisão crítica e fez sugestões à redação do manuscrito. 


\section{Referências}

BAUER, M.W.; AARTS, B. A construção do corpus: um princípio para a coleta de dados qualitativos. In: BAUER, M.W.; GASKEL, G. (Eds.). Pesquisa qualitativa com texto, imagem e som: um manual prático. Trad. Pedrinho A. Guareschi. 2.ed. Petrópolis: Vozes, 2003. p.39-63.

BERTEVELLO, G. Academias de ginástica e condicionamento físico: sindicatos e associações. In: DACOSTA, L.P. (Org.). Atlas do esporte no Brasil: atlas do esporte, educação física e atividades físicas de saúde e lazer no Brasil. Rio de Janeiro: Shape, 2005. p.65-6.

BRISOLLA, F. Próxima estação: fim de academia na lagoa provoca rixa entre alunos e vaivém de professores no mercado "fitness" da Zona Sul carioca. Rev. O Globo, v.8, n.398, p.8-11, 2012.

COELHO FILHO, C.A.A. O discurso do profissional de ginástica em academia no Rio de Janeiro. Movimento, v.6, n.12, p.14-24, 2000/1.

CORBIN, J.M. The body in hand illness. Qual. Health Res., v.13, n.2, p.256-67, 2003.

DAMICO, J. Rasuras disciplinares e amputação de fazeres. Movimento, v.17, n.3, p.269-87, 2011.

DEBERT, G.G. A antropologia e o estudo dos grupos e das categorias de idade. In: BARROS, M.M.L. (Org.). Velhice ou terceira idade? Estudos antropológicos sobre identidade, memória e política. 4.ed. Rio de Janeiro: Ed. FGV, 2007. p.49-67.

. A reinvenção da velhice: socialização e processos de reprivatização do envelhecimento. São Paulo: EDUSP, FAPESP, 2004.

DENZIN, N.K.; LINCOLN, Y.S. Introdução: a disciplina e a prática da pesquisa qualitativa. In: ___ (Orgs.) O planejamento da pesquisa qualitativa: teorias e abordagens. Trad. Sandra Regina Netz. Porto Alegre: Artmed, 2006. p.15-41.

FARIAS, G.O. et al. Carreira docente em educação física: uma abordagem sobre a qualidade de vida no trabalho de professores da rede estadual de ensino do Rio Grande do Sul. Rev. Educ. Fís. UEM, v.19, n.1, p.11-22, 2008.

FARIA JUNIOR, A.G.; FARIA, E.J.C. Didática de Educação Física. In: FARIA JUNIOR, A.G. et al. (Orgs.). Uma introdução à Educação Física. Niterói: Corpus, 1999. p.341-83.

FLICKER, S.; HAANS, D.; SKINNER, H. Ethical dilemmas in research on internet communities. Qual. Health Res., v.14, n.1, p.124-34, 2004.

FOLLE, A.; NASCIMENTO, J.V. Preocupações ao longo da carreira docente: estudos de caso com professores de educação física do magistério público estadual. Rev. Bras.

Cienc. Esp., v.33, n.4, p.841-56, 2011.

FOLLE, A. et al. Carreira no magistério público e nível de qualidade de vida no trabalho docente em Educação Física. Motriz, v.14 n.3, p.210-21, 2008.

FREITAS, D.C. et al. As práticas corporais nas academias de ginástica: um olhar do professor sobre o corpo fluminense. Rev. Bras. Cienc. Esp., v.33, n.4, p.959-74, 2011.

GASKELL, G. Entrevistas individuais e grupais. In: BAUER, M.W.; GASKEL, G. (Eds.). Pesquisa qualitativa com texto, imagem e som: um manual prático. Trad. Pedrinho A. Guareschi. 2.ed. Petrópolis: Vozes, 2003. p.64-89.

HUBERMAN, M. O ciclo de vida profissional dos professores. In: NÓVOA, A. (Org.). Vida de professores. 2.ed. Porto: Porto Editora, 2007. p.31-61.

HUNGER, D.A.C.F. et al. Formação acadêmica em Educação Física: "corpos" (docente e discente) de conhecimentos fragmentados. Motriz, v.15, n.1, p.79-91, 2009. 
LANGDON, E.J.; WIIK, F.B. Antropologia, saúde e doença: uma introdução ao conceito de cultura aplicado às ciências da saúde. Rev. Latino-am. Enferm., v.18, n.3, p.173-81, 2010.

LE BRETON, D. Antropologia do corpo e modernidade. Petrópolis: Vozes, 2011.

A sociologia do corpo. Petrópolis: Vozes, 2006.

LEMOYNE, J. et al. Occupational health problems and injuries among Quebec's physical educators. Appl. Ergon., v.38, n.5, p.625-34, 2007.

LÜDORF, S.M.A. Corpo e formação de professores. Interface (Botucatu), v.13, n.28, p.99-110, 2009.

MINAYO, M.C.S.; COIMBRA JÚNIOR, C.A.E. (Orgs.). Antropologia, saúde e envelhecimento. 2.ed. Rio de Janeiro: Ed. Fiocruz, 2004.

NÓVOA, A. Os professores e as histórias da sua vida. In: professores. 2.ed. Porto: Porto Editora, 2007. p.11-30. (Org.). Vida de

ORTEGA, F; ZORZANELLI, R. Corpo em evidência: a ciência e a redefinição do humano. Rio de Janeiro: Civilização Brasileira, 2010.

ORTEGA, F. O corpo incerto: corporeidade, tecnologias médicas e cultura contemporânea. Rio de Janeiro: Garamond, 2008.

PALMA, A. et al. Trabalho e saúde: o caso dos professores de educação física que atuam em academias de ginástica. Cad. IPUB/UFRJ, v.13, p.11-30, 2007.

PECORA, A.F.; ANJOS, P.M.; PAREDES, E.C. O envelhecimento como processo social. Rev. Educ. Publica, v.19, n.39, p.55-73, 2010.

SHILLING, C. The body and social theory. 2.ed. London: Sage Publications, 2005.

SILVA, A.C.; LÜDORF, S.M.A. Possíveis relações entre corpo, saúde e o envelhecimento do professor de Educação Física. Movimento, v.18, n.2, p.187-204, 2012.

. Envelhecendo como professor de Educação Física: um olhar sobre o corpo e a profissão. Rev. Educ. Fis. UEM, v.21, n. 4, p.645-54, 2010.

SILVA, A.C.; SILVA, F.A.G.; LÜDORF, S.M.A. Formação em Educação Física: uma análise comparativa de concepções de corpo de graduandos. Movimento, v.17, n.2, p.57-74, 2011.

STANO, R.C.M.T. Identidade do professor no envelhecimento. São Paulo: Cortez, 2001.

TARDIF, M. Saberes docentes e formação profissional. Petrópolis: Vozes, 2002.

TURATO, E.R. Tratado da metodologia da pesquisa clínico-qualitativa: construção teórico-epistemológica, discussão comparada e aplicação nas áreas da saúde e humanas. 2.ed. Petrópolis: Vozes, 2003. 
LÜDORF, S.M.A.; ORTEGA, F.J.G. Marcas en el cuerpo, cansancio y experiencia: matices del envejecer cómo profesor de Educación Física. Interface (Botucatu), v.17, n.46, p.661-75, jul./set. 2013.

Los objetivos de la investigación fueron comprender e interpretar los significados que los profesores de Educación Física atribuyen al cuerpo y al envejecimiento e investigar en que medida esas representaciones podrían influenciar su práctica profesional. Esta investigación, de naturaleza cualitativa, fue realizada con 43 profesores de escuelas y gimnasios que tenían más o menos 30 años de profesión. Los datos fueron interpretados por el análisis de contenido. El proceso de envejecimiento del profesor propicia madurez, experiencia y confianza en el trabajo, pero el cuerpo físico parece desprenderse del sujeto, repercutiendo en sentimientos contradictorios relacionados al envejecimiento. En los gimnasios, hay un ajuste al contexto de visibilidad, pues son valorizadas las potencialidades del cuerpo y las marcas de salud impresas en el cuerpo. Ya el desgaste y cansancio son sentidos por los ofesores que actúan en la escuela.

Palabras clave: Cuerpo. Envejecimiento. Educación Física. Salud. Profesión. 
